\title{
Composition and Cloud Structure of Jupiter's Deep Atmosphere
}

\author{
Sushil K. Atreya \\ Department of Atmospheric, Oceanic and Space Sciences, University of \\ Michigan, 2455 Hayward Street, Ann Arbor, MI 48109 USA \\ Paul R. Mahaffy, Hasso B. Niemann \\ Goddard Space Flight Center, Greenbelt, MD 20771 USA \\ Tobias C. Owen \\ University of Hawaii, Institute for Astronomy, 2680 Woodlawn Drive, \\ Honolulu, HI 96822 USA
}

\begin{abstract}
Abundances of ammonia, hydrogen sulfide, water, methane and other hydrocarbons, noble gases and their isotopes, etc. were measured for the first time to the 22 bar level. The ratios of the heavy elements to hydrogen were found to be enriched by a factor of 2-3 relative to solar, implying a large influx of cold planetesimals into Jupiter.
\end{abstract}

\section{Introduction}

On December 7, 1995, Galileo Probe became the first probe ever to enter into a giant planet. It descended into the atmosphere of Jupiter at a planetocentric latitude of $6.53^{\circ} \mathrm{N}$ and a System III longitude of $4.88^{\circ} \mathrm{W}$ (Young 1998). The Probe made the first in situ measurements of the chemical composition, cloud structure, net radiative flux, winds, temperature, pressure, turbulence, and lightning in the atmosphere of Jupiter. The attenuation of the probe-orbiter radio signal was studied to infer atmospheric properties. The Probe Neutral Mass Spectrometer (GPMS) made the first direct and in situ measurement of the composition of Jupiter's atmosphere from 0.5 bar to a depth of $132 \mathrm{~km}$ (below 1 bar) where a pressure of 22 bar was reached. A combination of the GPMS results with those from the probe radio relay and the Net Flux Radiometer provides us with the first comprehensive view of Jupiter's deep atmospheric composition.

\section{Galileo Probe Measurements and their Implications}

We present in Tables 1 and 2 a list of all measured constituents, elemental abundances and the isotopic ratios (existing data for Saturn are listed for comparison). Several things are noteworthy. The subsolar abundance of helium in Jupiter's atmosphere is attributed to the loss of this species by condensation in Jupiter's interior; the same applies to Saturn. The depletion of neon in 
Table 1. Mixing ratios rel. $\mathrm{H}_{2}$ of the Atmospheres of Jupiter and Saturn

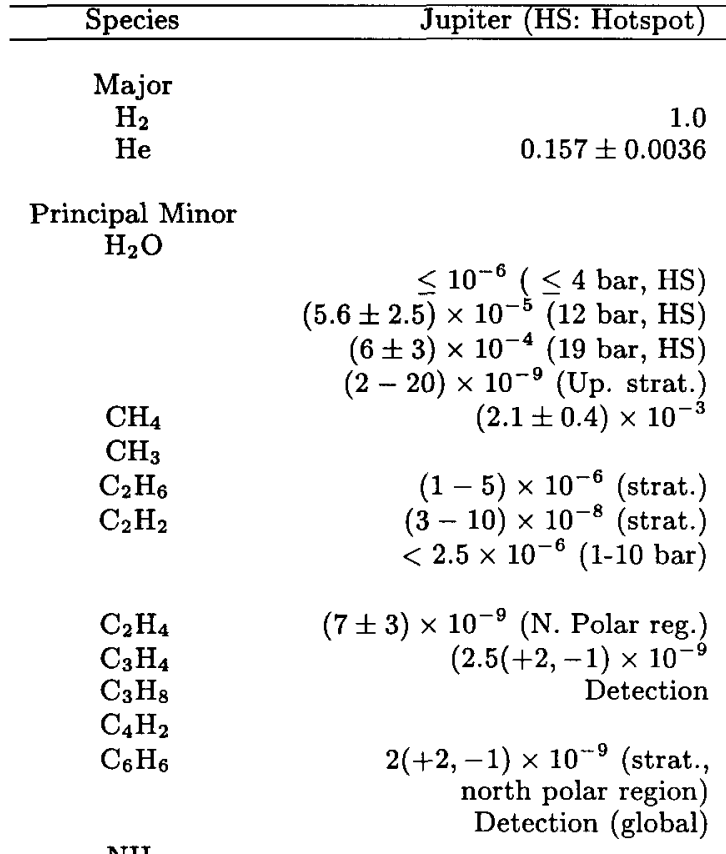

$\mathrm{NH}_{3}$

$\mathrm{H}_{2} \mathrm{~S}$

$$
\begin{array}{r}
(0.2-1) \times 10^{-5}(0.5-2 \text { bar, HS }) \\
(3.3 \pm 1.5) \times 10^{-4}(4 \text { bar, HS }) \\
(8.1 \pm 1.2) \times 10^{-4}(\geq 8 \text { bar, HS }) \\
<1 \times 10^{-7}(\leq 4 \text { bar }) \\
7 \times 10^{-6}(8.7 \text { bar }) \\
(7.7 \pm 0.5) \times 10^{-5}(\geq 16 \text { bar })
\end{array}
$$

greatly subsat. ( $\mathrm{p} \geq 3$ bar) $(2-20) \times 10^{-9}(\mathrm{p}<0.3 \mathrm{mb})$

$$
\begin{array}{r}
4.5(+2.4,-1.9) \times 10^{-3} \\
(1.5-7.5) \times 10^{13} \mathrm{~cm}^{-2}(\text { strat. }) \\
(3 \pm 1) \times 10^{-6}(\text { strat. }) \\
(2.1 \pm 1.4) \times 10^{-7}(\text { strat. } / 20- \\
50 \mathrm{mb}, \mathrm{N} \text {. hemisph. }) \\
(5 \pm 1) \times 10^{-8}(\text { S. hemisph. }) \\
6 \times 10^{-10}(10 \mathrm{mb}) \\
9 \times 10^{-11}(10 \mathrm{mb}) \\
2.5 \times 10^{-10}(<10 \mathrm{mb}) \\
(\text { global avg./strat. }) \\
6 \times 10^{-4} \text { (global) } \\
\end{array}
$$

Disequilibrium

$$
\begin{array}{cr}
\mathrm{PH}_{3} & (1-2) \times 10^{-7}(0.2-0.6 \mathrm{bar}) \\
& 6 \times 10^{-7}(>1 \mathrm{bar}) \\
\mathrm{CO} & 1.6 \times 10^{-9} \\
\mathrm{CO}_{2} & \text { Detection }(<10 \mathrm{mb}) \\
\mathrm{GeH}_{4} & (7 \pm 2) \times 10^{-10} \\
\mathrm{AsH}_{3} & (2.2 \pm 1.1) \times 10^{-10}
\end{array}
$$

$$
\begin{array}{r}
1 \times 10^{-5}(800 \mathrm{mb}) \\
7(+3,-2) \times 10^{-6}(>400 \mathrm{mb}) \\
(3 \pm 1) \times 10^{-6}(100-1000 \mathrm{mb}) \\
(1 \pm 0.3) \times 10^{-9} \\
3 \times 10^{-10}(<10 \mathrm{mb}) \\
(4 \pm 4) \times 10^{-10} \\
(3 \pm 1) \times 10^{-9}
\end{array}
$$

Other Minor

$\begin{array}{cr}\mathrm{H} & \text { Variable } \\ \left(\mathrm{H}_{2}\right)_{2} & \text { Variable } \\ \mathrm{H}_{3}^{+} & \text {Variable } \\ \mathrm{HCl} & \\ \mathrm{Cl} & \text { tentative detection }\end{array}$


Table 2. Elemental and Isotopic Abundances

Elemental ratios

\begin{tabular}{|c|c|c|c|}
\hline Elements & Sun (a) & Jupiter/Sun & Saturn/Sun \\
\hline $\mathrm{He} / \mathrm{H}$ & 0.0975 & $0.807 \pm 0.02$ & $\begin{array}{r}0.56-0.85(\mathrm{~b}) \\
\sim 0.2 \pm 0.1(1984 \text { result })\end{array}$ \\
\hline $\mathrm{Ne} / \mathrm{H}$ & $1.23 \times 10^{-4}$ & $0.10 \pm 0.01(\mathrm{c})$ & \\
\hline $\mathrm{Ar} / \mathrm{H}$ & $3.62 \times 10^{-6}$ & $2.5 \pm 0.5(\mathrm{c})$ & \\
\hline $\mathrm{Kr} / \mathrm{H}$ & $1.61 \times 10^{-9}$ & $2.7 \pm 0.5(\mathrm{c})$ & \\
\hline $\mathrm{Xe} / \mathrm{H}$ & $1.68 \times 10^{-10}$ & $2.6 \pm 0.5(\mathrm{c})$ & \\
\hline $\mathrm{C} / \mathrm{H}$ & $3.62 \times 10^{-4}$ & $2.9 \pm 0.5$ & $\sim 6$ \\
\hline $\mathrm{N} / \mathrm{H}$ & $1.12 \times 10^{-4}$ & $3.6 \pm 0.5:$ HS & $2-4$ (uncertain) \\
\hline $\mathrm{O} / \mathrm{H}$ & $8.51 \times 10^{-4}$ & $\begin{array}{r}0.033 \pm 0.015: \\
\text { HS, } 12 \text { bar } \\
0.35: \\
\text { HS, } 19 \text { bar }\end{array}$ & \\
\hline $\mathrm{P} / \mathrm{H}$ & $3.73 \times 10^{-7}$ & 0.82 & $5-10$ \\
\hline $\mathrm{S} / \mathrm{H}$ & $1.62 \times 10^{-5}$ & $2.5 \pm 0.15$ & \\
\hline \multicolumn{4}{|c|}{ Isotopic ratios } \\
\hline Elements & Sun & Jupiter & Saturn \\
\hline${ }^{13} \mathrm{C} /{ }^{12} \mathrm{C}$ & 0.011 & $0.0108 \pm 0.0005$ & 0.011 \\
\hline${ }^{14} \mathrm{~N} /{ }^{15} \mathrm{~N}$ & & $430 \pm 50(d)$ & \\
\hline${ }^{136} \mathrm{Xe} / \mathrm{Xe}$ & & $0.076 \pm 0.126(\mathrm{c})$ & \\
\hline${ }^{134} \mathrm{Xe} / \mathrm{Xe}$ & & $0.091 \pm 0.074(\mathrm{c})$ & \\
\hline${ }^{132} \mathrm{Xe} / \mathrm{Xe}$ & & $0.290 \pm 0.068(\mathrm{c})$ & \\
\hline${ }^{131} \mathrm{Xe} / \mathrm{Xe}$ & & $0.203 \pm 0.088(\mathrm{c})$ & \\
\hline${ }^{130} \mathrm{Xe} / \mathrm{Xe}$ & & $0.038 \pm 0.138(\mathrm{c})$ & \\
\hline${ }^{129} \mathrm{Xe} / \mathrm{Xe}$ & & $0.285 \pm 0.075(\mathrm{c})$ & \\
\hline${ }^{128} \mathrm{Xe} / \mathrm{Xe}$ & & $0.018 \pm 0.094(\mathrm{c})$ & \\
\hline${ }^{20} \mathrm{Ne} /{ }^{22} \mathrm{Ne}$ & $13.81 \pm 0.08$ & $13 \pm 2(\mathrm{c})$ & \\
\hline${ }^{3} \mathrm{He} /{ }^{4} \mathrm{He}$ & $\begin{array}{r}(1.5 \pm 0.3) \times 10^{-4} \\
(\text { meteoritic) }\end{array}$ & $(1.66 \pm 0.05) \times 10^{-4}$ & \\
\hline $\mathrm{D} / \mathrm{H}$ & $\begin{array}{r}(3.0 \pm 0.17) \times 10^{-5} \\
(2.6 \pm 1.0) \times 10^{-5}\end{array}$ & $\begin{array}{r}(2.6 \pm 0.7) \times 10^{-5} \\
1.8(+1.1,-0.5) \times 10^{-5}\end{array}$ & $(2.3 \pm 1) \times 10^{-5}$ \\
\hline
\end{tabular}
(a) Anders \& Grevesse 1989
(b) Conrath \& Gautier 2000
(c) Mahaffy et al. 2000a
(d) Mahaffy et al. $2000 \mathrm{~b}$ 
Jupiter's atmosphere is most likely the result of differentiation of this gas into helium droplets which carry neon with them as they precipitate to the core of Jupiter. So far, $\mathrm{P}$ (as $\mathrm{PH}_{3}$ ) has been measured on Jupiter only to a shallow depth where the pressure is approximately 1 bar. The elemental ratios (to $\mathrm{H}$ ) of the heavy noble gases, argon, xenon and krypton, are found to be a factor of 2-3 greater than their solar values (Mahaffy et al. 2000a). C, N and S are similarly enriched, as seen in Table 2 (The reader is referred to Atreya et al. 1999 and Niemann et al. 1998 and citations therein for complete references on most of the table listings and other material in this paper).

The probe measured greatly depleted abundances of the condensible volatiles $\left(\mathrm{NH}_{3}, \mathrm{H}_{2} \mathrm{~S}\right.$, and $\left.\mathrm{H}_{2} \mathrm{O}\right)$ to depths well below their expected condensation levels. Contrary to the expectations, only very thin wispy clouds were detected in the Galileo Probe entry region. However, the tenuous cloud at $1.3 \mathrm{bar}$, an equally tenuous one at 0.5 bar, perhaps a very thin condensate layer at $1.6 \mathrm{bar}$, and some particles down to 4 bar in the probe site are consistent with the clouds of $\mathrm{NH}_{3}$ ice (at $0.5 \mathrm{bar}$ ), $\mathrm{NH}_{4} \mathrm{SH}$-ice $\left(1.3 \mathrm{bar}\right.$ ) and $\mathrm{H}_{2} \mathrm{O}$-ice $(1.6 \mathrm{bar}$ ), respectively, based on the actual measured abundances of the condensible volatiles that were also highly depleted. The extreme dryness in the upper regions, along with a trend of increasing mixing ratios of the condensible volatiles along the probe's trajectory, has been variously attributed to local meteorology in the form of downdrafts or waves. Finally, the oxygen abundance in the deep well-mixed atmosphere continues to remain a mystery, as the water mixing ratio was still increasing even at a depth corresponding to 22 bar, the deepest level probed. Ground-based microwave data imply a depletion in ammonia, but to much shallower depths $(p<3-4$ bar) than the probe (to 8-10 bar), and show variations from Jupiter's belts to zones. In fact, unlike the probe entry site, the Galileo orbiter imaging shows that the clouds of ammonia are nearly ubiquitous on Jupiter. Moreover, they are located at $0.75 \pm 0.25$ bar, consistent with the thermochemical equilibrium cloud models assuming 1-3 $\times$ solar $\mathrm{N} / \mathrm{H}$. Although the situation with water is less satisfactory, as its abundance in the deep well-mixed atmosphere is not known anywhere, not even in the probe entry site, it is already apparent from the Galileo orbiter Near Infrared Mapping Spectrometer (Roos-Serote et al. 2000) and the imaging (Gierasch et al. 2000; Ingersoll et al. 2000) that there are variations in the water vapor relative humidity from place to place. Unlike the probe region, where the clouds were nearly non-existent, the imaging of a storm $50 \mathrm{~km}$ in vertical extent and $4000 \mathrm{~km}$ in length in the $\left(14^{\circ} \mathrm{S}, 268^{\circ} \mathrm{W}\right)$ and $\left(15^{\circ} \mathrm{S}, 263^{\circ} \mathrm{W}\right)$ region shows an optically thick cloud with condensation extending to at least the 3-bar level. This cloud has been attributed to a water cloud, the only species that is expected to condense in this region. Analysis of the other regions is continuing. This is an exciting development, since it shows that the greatly subsaturated and subsolar water of the probe region is not representative of Jupiter as a whole. Unfortunately, the imaging data show only the top of the convective cloud whose base could lie much deeper - 5.7 bar for solar $\mathrm{O} / \mathrm{H}, 7.2$ bar for $3 \times$ solar, and 12 bar if it were $10 \times$ solar. Thus, the oxygen elemental abundance in the deep well-mixed atmosphere of Jupiter continues to be unknown.

The supersolar ratios of the heavy elements, C, N, S, and the heavy noble gases, $\mathrm{Ar}, \mathrm{Kr}$, and $\mathrm{Xe}$, all enriched by a factor of $2-3$, argue for a major contribution of the heavy elements to Jupiter by icy planetesimals. Unfortunately, 
the abundance of the "carrier", water, is unknown. Nevertheless, the nitrogen and argon enrichment, in particular, suggests that the planetesimals formed at a temperature of $\leq 30 \mathrm{~K}$ (Owen et al. 1999). This is much lower than the temperature in the Uranus-Neptune region where most (Oort's cloud) comets formed or in the current orbit of Jupiter. This finding has profound implications for the formation of Jupiter and the evolution of its atmosphere.

\section{Conclusion}

Despite the overwhelming success of the Galileo mission, many fundamental questions about the composition that are critical for understanding the planetary formation remain unanswered. Ideally, a complete map of the abundance profiles of all heavy elements, and at the very least that of nitrogen and oxygen (from ammonia and water), to the deep well-mixed atmosphere of Jupiter are essential for determining whether the probe results are applicable to Jupiter as a whole. Cleverly instrumented multiprobes reaching $50-100$ bar into the atmosphere of Jupiter will be needed to answer fundamental questions about the formation of this giant planet and its atmosphere.

\section{References}

Anders, E., \& Grevesse, N. 1989, Geochim. Cosmochim. Acta, 53, 197

Atreya, S. K., Wong, M.H., Owen, T.C., Mahaffy, P.R., Niemann, H.B., de Pater, I., Drossart, P., \& Encrenaz, Th. 1999, Planet. Space Sci., 47, 1243

Conrath, B. J., \& Gautier, D. 2000, Icarus, 144, 124

Gierasch, P. J., Ingersoll, A. P., Banfield, D., Ewald, S. P., Helfenstein, P., SimonMiller, A., Vasavada, A., Breneman, H.H., Senske, D. A., \& the Galileo Imaging Team 2000, Nature, 403, 628

Ingersoll, A. P., Gierasch, P. J., Banfield, D., Vasavada, A., \& the Galileo Imaging Team 2000, Nature, 403, 630

Mahaffy, P.R., Niemann, H.B., Alpert, A., Atreya, S. K., Demick, J., Donahue, T. M., Harpold, D. N., \& Owen, T. C. 2000a, JGR Planets, 105, 15061

Mahaffy, P.R., Niemann, H.B., Atreya, S.K., Wong, M.H., \& Owen, T.C. 2000b, BAAS, 32, in press

Niemann, H.B., Atreya, S.K., Carignan, G.R., Donahue, T.M., Haberman, J.A., Harpold, D.N., Hartle, R.E., Hunten, D. M., Kasprzak, W.T., Mahaffy, P. R., Owen, T. C., \& Way, S. H. 1998, JGR, 103, 22831

Owen, T. C., Mahaffy, P. R., Niemann, H.B., Atreya, S. K., Bar-Nun, A., Donahue, T. M., \& de Pater, I. 1999, Nature, 402, 269

Roos-Serote, M., Vasavada, A., Kamp, L., Drossart, P., Irwin, P., Nixon, C., \& Carlson, R. W. 2000, Nature, 405, 158

Young, R.E. 1998, JGR, 103, 22775 